\title{
Thermal and chemical inactivation of Lactobacillus virulent bacteriophage
}

\author{
X. Chen, Y. Liu, M. Fan, Z. Wang, W. Wu, and J. Wang ${ }^{1}$ \\ Key Laboratory of Dairy Biotechnology and Engineering, Ministry of Education, Inner Mongolia Agricultural University, Hohhot, 010018 , \\ P. R. China
}

\section{ABSTRACT}

The effect of thermal treatments and several biocides on the viability of Lactobacillus virulent phage P1 was evaluated. Times to achieve $99 \%$ inactivation $\left(T_{99}\right)$ of phage at different treatment conditions were calculated. The thermal treatments applied were 63,72 , and $90^{\circ} \mathrm{C}$ in 3 suspension media (de Man, Rogosa, Sharpe broth, reconstituted skim milk, and Tris magnesium gelatin buffer). Phage P1 was completely inactivated in 5 and 10 min at 90 and $72^{\circ} \mathrm{C}$, respectively; however, reconstituted skim milk provided better thermal protection at $63^{\circ} \mathrm{C}$. When phage $\mathrm{P} 1$ was treated with various biocides, $800 \mathrm{mg} / \mathrm{L}$ of sodium hypochlorite was required for total inactivation $(\sim 7.3 \log$ reduction $)$ within 60 min, whereas treatment with $100 \%$ ethanol resulted in only a $\sim 4.7 \log$ reduction, and $100 \%$ isopropanol resulted in a 5.2-log reduction. Peracetic acid (peroxyacetic acid) at the highest concentration used (0.45\%) resulted in only a $\sim 4$.- $\log$ reduction of phage within $60 \mathrm{~min}$. The results of this study provide additional information on effective treatments for the eradication of potential phage infections in dairy plants.

Key words: Lactobacillus virulent bacteriophage, thermal treatment, chemical treatment, inactivation

\section{INTRODUCTION}

Lactobacillus plantarum is a versatile mesophilic lactic acid bacterium (LAB) that constitutes parts of the natural microflora of dairy, meat, and vegetables, as well as fermented foods, and it is closely associated with human health (de Vries et al., 2006). Some strains express high resistance to extreme intestinal conditions, including gastric acidity and bile toxicity, and therefore can be utilized as probiotic cultures (Karasu et al., 2010; Briggiler Marcó et al., 2012). In the dairy industry, L. plantarum is used as a starter culture

Received December 14, 2016.

Accepted May 12, 2017.

${ }^{1}$ Corresponding author: imwjc@163.com to produce cheese, yogurt, and Lactobacillus-based probiotic beverages. When L. plantarum is used as a starter culture in Cheddar cheese manufacture, it has been shown to influence the formation of important aroma compounds. In addition, the culture has been demonstrated to accelerate the speed of cheese ripening (Lynch et al., 1999).

Bacteriophage infection is considered an important economic problem worldwide in food fermentation. Phage particles in a food plant can disseminate quickly, lysing starter cultures and resulting in poor quality or unsafe food because slow or complete starter failure results in poor acid production (Zhang et al., 2015). In fermented foods, the phage gains entry via raw milk, contaminated bacterial cultures, air, and processing equipment (Moineau, 1999; Madera et al., 2004). In most cases, raw milk is pasteurized before starter culture addition, and equipment is sanitized to reduce the presence of spoilage bacteria. Decreasing the incidence of phage infection via proper thermal treatment of milk and the use of effective biocides on equipment not only results in greater economic savings but also assures greater safety of the food products. Overall, information on the chemical and thermal resistance of Lactobacillus phages used in the dairy industry is limited because it often tends to be phage-specific.

Virulent phage P1 was initially isolated from a slow fermentation containing L. plantarum IMAU10120. The phage was subsequently shown to belong to the Siphoviridae family. The latent period of this phage was 45 min with a burst time of 90 min; the burst size was $132.88 \pm 2.37$ phage counts expressed per $\mathrm{mL}$ per infective center. This phage exhibited good tolerance $(>95 \%$ survival) when treated at $0,10,20,30,37,42$, and $50^{\circ} \mathrm{C}$; however, incubation at $50^{\circ} \mathrm{C}$ decreased adsorption; maximum adsorption was observed between 30 and $42^{\circ} \mathrm{C}$ (Chen et al., 2016).

The aim of the present research was to investigate the effect of thermal treatments and biocides routinely used in dairy plants and laboratories to limit phage infection and thereby contribute to the increased awareness of phage resistance. 


\section{MATERIALS AND METHODS}

\section{Bacteria Strain, Phage, and Culture Conditions}

Lactobacillus plantarum IMAU10120 was used as the host strain for the Lactobacillus virulent phage P1 and was obtained from the Lactic Acid Bacteria Collection Center of the Key Laboratory of Dairy Biotechnology and Engineering, Ministry of Education, Inner Mongolia Agricultural University, P.R. China.

The organism was grown at $37^{\circ} \mathrm{C}$ in de Man, Rogosa, and Sharpe (MRS) broth (Difco, Becton Dickinson and Co., Franklin Lakes, NJ) for 24 h. For phage amplification, MRS was supplemented with $10 \mathrm{mM}$ $\mathrm{CaCl}_{2}$. Phage stocks were prepared as previously described (Neviani et al., 1992) and stored as lysates at $4^{\circ} \mathrm{C}$. Phage counts, expressed as plaque-forming units (pfu) per milliliter, were obtained using a plaque assay method with modification (Quiberoni et al., 2011). In brief, $100 \mu \mathrm{L}$ of phage suspension was mixed with host bacterial suspended in a top layer of melted MRS agar (20 mL, 0.7\% wt/vol agar) containing $10 \mathrm{mM} \mathrm{CaCl} 2$ and maintained at $46^{\circ} \mathrm{C}$. The top layer was immediately poured into petri dishes $(90 \mathrm{~mm})$ containing a bottom layer of MRS agar (1.5\% wt/vol agar). All plates were incubated at $37^{\circ} \mathrm{C}$ for 16 to $18 \mathrm{~h}$ before they were examined for plaques.

\section{Thermal Treatments}

To evaluate the heat resistance of phage, 3 temperatures $\left(63,72\right.$, and $\left.90^{\circ} \mathrm{C}\right)$ were used together with 3 suspension media: (1) MRS broth; (2) reconstituted skim milk (RSM; 10\%, wt/vol); and (3) Tris magnesium gelatin buffer (TMG; $10 \mathrm{mM}$ Tris-HCl, $10 \mathrm{mM}$ $\mathrm{MgSO}_{4}$, and $0.1 \%$ (wt/vol) gelatin, $\mathrm{pH} 7.4$; Briggiler Marcó et al., 2009). The temperatures selected were based on routine pasteurization treatments used in the dairy industry. The suspension media used in the present investigation are commonly used in laboratories or dairy plants for starter culture propagation.

Phage P1 (approximately $10^{8} \mathrm{pfu} / \mathrm{mL}$ ) was mixed with each suspension medium, and $1.0-\mathrm{mL}$ mixtures were distributed into a series of capped tubes and incubated at 1 of the 3 temperatures described above. At predetermined time intervals, the tubes were removed and cooled quickly in ice water. The surviving phages were counted using a plaque assay, and results were expressed as the concentration of active viral particles and plotted against time. Time (min) to achieve $99 \%$ inactivation $\left(\boldsymbol{T}_{\mathbf{9 9}}\right)$ was calculated graphically from survival curves, as described by Capra et al. (2004). Similar phage suspensions without heat treatment were used as controls.

\section{Biocide Treatments}

The biocides used included ethanol (10, 20, 30, 50, 75, and 100\%, vol/vol; Tianjin Fengchuan Chemical Reagent Technologies Co. Ltd., Tianjin, China); isopropanol (10, 30, 50, and 100\%, vol/vol; Tianjin Fengchuan Chemical Reagent Technologies Co. Ltd.); commercial sodium hypochlorite (100, 200, 400, $800 \mathrm{mg} / \mathrm{L}$; Shandong Lircon Medical Technology Inc., Shandong, China); and peracetic acid $(0.15,0.25$, and $0.45 \%$, vol/ vol; Tianjin Fengchuan Chemical Reagent Technologies Co. Ltd.). Sodium hypochlorite was diluted in phosphate buffer ( $\mathrm{pH} 7$ ). The alcohols and peracetic acid were diluted in distilled water. The resulting $\mathrm{pH}$ of the peracetic acid solution was 2.7. All assays were carried out at $25^{\circ} \mathrm{C}$.

For assessment of biocide efficacy, phage P1 $\left(\sim 10^{7}\right.$ $\mathrm{pfu} / \mathrm{mL}$ ) was mixed with a biocide solution and incubated at $25^{\circ} \mathrm{C}$. Similar phage suspensions without biocide addition but with $\mathrm{pH}$ adjustment were used as controls. At predetermined time intervals, the tubes were removed and the surviving phages counted as previously described. Results are expressed as the concentration of active viral particles and plotted against time. The $T_{99}$ was calculated from the survival curves.

\section{Statistical Analysis}

All data were analyzed using the Originpro software (version 8.6; Originlab, Northampton, MA). Experiments were replicated 3 times. Means were compared using a one-way ANOVA followed by SPSS Statistics 20 (IBM Corp., Armonk, NY); significance was declared at $P<0.05$.

\section{RESULTS}

\section{Thermal Treatment}

Survival of phage heated at 63 and $72^{\circ} \mathrm{C}$ in MRS broth, RSM, and TMG is shown in Figure 1. The greatest resistance was observed at $63^{\circ} \mathrm{C}$, regardless of suspension medium used. The $T_{99}$ values for phage at 72 and $90^{\circ} \mathrm{C}$, regardless of suspension medium, were $<5$ min. At $63^{\circ} \mathrm{C}, T_{99}$ values ranged from 7.55 to 9.89 min, depending on the suspension broth (Table 1). Overall, thermal resistance of phage appeared greatest in RSM.

Survival of phage P1 is shown in Figure 1; RSM and MRS provided the maximum and minimum protection to phage P1, respectively. Regardless of medium used, phage suspensions heated at 72 and $90^{\circ} \mathrm{C}$ were completely inactivated within 10 and 5 min, respectively. 


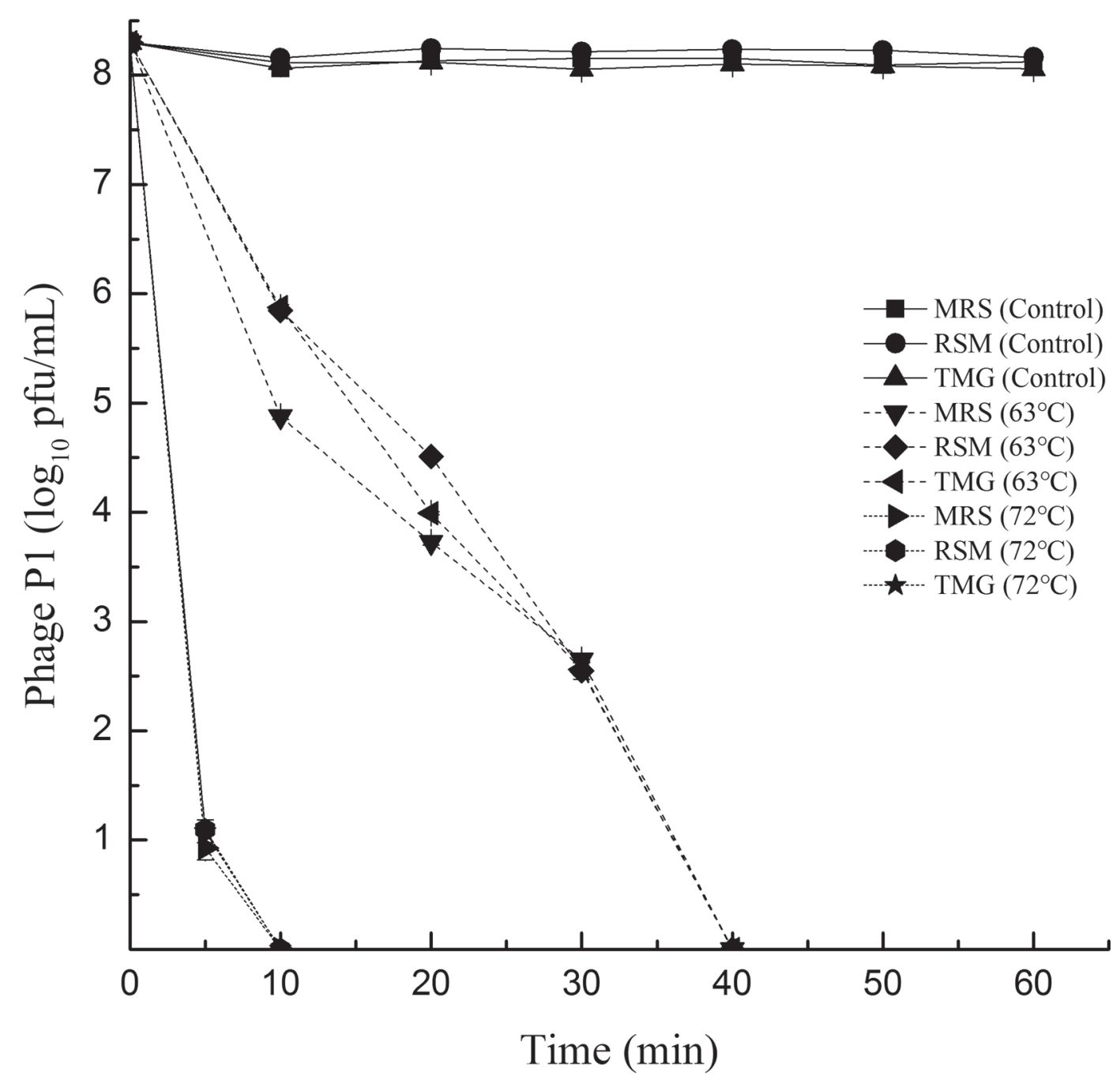

Figure 1. Thermal inactivation kinetics of phage P1 $\left(\log _{10}\right.$ plaque-forming units $\left./ \mathrm{mL}\right)$ at $25^{\circ} \mathrm{C}$ (control), $63^{\circ} \mathrm{C}$, and $72^{\circ} \mathrm{C}$ in de $\mathrm{Man}, \mathrm{Rogosa}$, Sharpe medium (MRS); reconstituted dry skim milk (RSM); and Tris magnesium gelatin buffer (TMG). Values are the mean of 3 determinations. Error bars are not shown and are \pm 0.11 .

Table 1. Thermal resistance of Lactobacillus virulent phage P1 in different suspension media

\begin{tabular}{|c|c|c|c|}
\hline \multirow[b]{2}{*}{ Medium $^{1}$} & \multicolumn{3}{|c|}{$T_{99}^{2}(\min )$} \\
\hline & $63^{\circ} \mathrm{C}$ & $72^{\circ} \mathrm{C}$ & $90^{\circ} \mathrm{C}$ \\
\hline $\begin{array}{l}\text { MRS broth } \\
\text { RSM } \\
\text { TMG buffer }\end{array}$ & $\begin{array}{l}7.55 \pm 0.07^{\mathrm{c}} \\
9.89 \pm 0.01^{\mathrm{a}} \\
9.42 \pm 0.06^{\mathrm{b}}\end{array}$ & $\begin{array}{l}<5 \\
<5 \\
<5\end{array}$ & $\begin{array}{l}<5 \\
<5 \\
<5\end{array}$ \\
\hline
\end{tabular}

${ }^{\mathrm{a}-\mathrm{c}}$ Within a column, means with different letters are significantly different $(P<0.05)$.

${ }^{1} \mathrm{MRS}=$ de Man, Rogosa, Sharpe medium; RSM = reconstituted dry skim milk; TMG = Tris magnesium gelatin

${ }^{2}$ Time required for $99 \%$ inactivation of phage particles. Values are the mean $\pm \mathrm{SD}$ of 3 determinations.

\section{Chemical Treatments}

The $T_{99}$ values of phage when treated with different biocides are shown in Table 2. Variations in the time to achieve $T_{99}$ depended on the nature of the biocide and its concentration. Overall, increasing the biocide concentration resulted in a progressive increase in time required to achieve a 2-log phage reduction.

Although $100 \%$ ethanol resulted in the shortest time required to achieve $T_{99}$ inactivation of phage (Table 2), this concentration was unable to achieve a complete kill within $60 \mathrm{~min}$ and resulted in only a $\sim 4.7-\log$ reduction (Figure 2). Phage reductions with 10, 20, and $30 \%$ ethanol were $<1.70 \log$ with a $T_{99}>60 \mathrm{~min}$. As expected $75 \%$ ethanol ( $T_{99}=8.15 \mathrm{~min}$ ) was more effective than $50 \%$ ethanol ( $\left.T_{99}=16.86 \mathrm{~min}\right)$. 
Isopropanol $(100 \%)$ resulted in the highest phage inactivation (Figure 3); however, similar to $100 \%$ ethanol, it did not result in complete elimination of phage within $60 \mathrm{~min}$ ( $\sim 5.2-\log$ reduction). With $10 \%$ isopropanol, phage populations were observed to remain relatively unchanged ( $\left.T_{99}>60 \mathrm{~min}\right)$. As expected, $50 \%$ isopropanol $\left(T_{99}=24.21 \mathrm{~min}\right)$ was more effective than $30 \%$ isopropanol $\left(T_{99}=30.83 \mathrm{~min}\right)$.

Sodium hypochlorite at $100 \mathrm{mg} / \mathrm{L}$ exhibited little effect on phage P1 $\left(T_{99}>60 \mathrm{~min}\right.$; Figure 4$)$. At 200 $\mathrm{mg} / \mathrm{L}$, the $T_{99}$ remained $>60 \mathrm{~min}$ and resulted in only a 1.37-log reduction after $60 \mathrm{~min}$. Increasing the concentration to $400 \mathrm{mg} / \mathrm{L}$ resulted in a $T_{99}$ value of $46.44 \mathrm{~min}$ and a 2.15-log reduction. In contrast, phage treated with sodium hypochlorite at $800 \mathrm{mg} / \mathrm{L}$ exhibited a $T_{99}$ $=7.70 \mathrm{~min}$, with total inactivation within $60 \mathrm{~min}$.

The use of peracetic acid at $0.15 \%$ had little effect on the phage population $\left(T_{99}>60 \mathrm{~min}\right.$, Figure 5$)$. With $0.25 \%$ peracetic acid, a $\sim 2.5-\log$ reduction was observed with a $T_{99}$ value of $51.83 \mathrm{~min}$. Increasing the concentration to $0.45 \%$ further increased lethality, resulting in a $\sim 4.0-\log$ reduction after $60 \mathrm{~min}$ and a $T_{99}$ of $21.74 \mathrm{~min}$.

\section{DISCUSSION}

Phage infection, which can occur at any time during processing and after pasteurization, is the most prevalent reason for starter culture failure in the fermentation production of dairy and meat products. These failures and poor activity result in economic losses for the manufacturer and are a potential cause for foodborne illness. Research on methods to control the incidence of phage infection has therefore become important espe-

Table 2. Resistance of Lactobacillus virulent phage P1 to biocides

\begin{tabular}{llc}
\hline Biocide & Concentration & $T_{99}{ }^{1}(\mathrm{~min})$ \\
\hline Ethanol (\% vol/vol) & 10 & $>60$ \\
& 20 & $>60$ \\
& 30 & $>60$ \\
& 50 & $16.86 \pm 0.16^{\mathrm{a}}$ \\
& 75 & $8.15 \pm 0.07^{\mathrm{b}}$ \\
Isopropanol (\% vol/vol) & 100 & $>6.48 \pm 0.05^{\mathrm{c}}$ \\
& 10 & $30.83 \pm 0.32^{\mathrm{a}}$ \\
& 30 & $24.21 \pm 0.24^{\mathrm{b}}$ \\
Sodium hypochlorite (mg/L) & 100 & $8.10 \pm 0.12^{\mathrm{c}}$ \\
& 200 & $>60$ \\
& 400 & $>60$ \\
Peracetic acid (\% vol/vol) & 800 & $46.44 \pm 0.88$ \\
& 0.15 & $>60 \pm 0.18$ \\
& 0.25 & $51.83 \pm 1.43$ \\
& 0.45 & $21.74 \pm 0.26$ \\
\hline
\end{tabular}

$\overline{{ }^{\mathrm{a}-\mathrm{c}} \text { Means within a column and within the same biocide with different }}$ letters are significantly different $(P<0.05)$.

${ }^{1}$ Time required for $99 \%$ inactivation of phage particles. Values are the mean \pm SD of 3 determinations. cially in the development of new fermentation products including functional foods. The vast majority of intervention methods rely on good manufacturing practices (GMP) and, in particular, the application of sanitizers or biocides and heat to eliminate phage from equipment and air. In this respect, various criteria are used to evaluate efficacy. One of the most commonly used is $T_{99}$, which is the time required to reduce $99 \%$ of the most sensitive phage in a population under specified conditions. This criterion has been reported to yield a very good approximation of phage resistance to inactivation treatments (Guglielmotti et al., 2012).

In dairy plants, raw milk is most often subjected to thermal treatment to eliminate many microorganisms, including spoilage pathogens, thus assuring safety and a longer shelf life (Guglielmotti et al., 2012). In this respect, the thermal resistance characteristics of Lactobacillus virulent phage P1, isolated from a starter culture failure vat, would be of importance when used as an intervention strategy.

In general, mesophilic LAB phages have been reported to exhibit a wide range of heat resistance. This may indicate that, at least for some, phage thermal treatment is phage-specific. For example, Ebrecht et al. (2010) investigated the efficiency of thermal treatments normally used in dairy plants, on 3 virulent (BYM, YAB, and Ib3) and 2 temperate (Cb1/204 and Cb1/342) Lactobacillus delbrueckii bacteriophages. The authors reported that the 2 temperate phages showed relatively low heat resistance, with a $T_{99}<2$ min at $63^{\circ} \mathrm{C}$ in MRS broth, and a $T_{99}<2.4$ min for all phages at $72^{\circ} \mathrm{C}$. In contrast, Briggiler Marcó et al. (2009) reported that 4 phages (ATCC8014-B1, ATCC8014-B2, FAGK1, FAGK2) specific to L. plantarum expressed relatively high heat resistance at $63^{\circ} \mathrm{C}\left(T_{99}>45 \mathrm{~min}\right)$ and much higher resistance at $72^{\circ} \mathrm{C}$ when reconstituted skim milk was used as heating medium. Pujato et al. (2014) reported that 9 Leuconostoc mesenteroides phages isolated from blue cheese manufacture generally showed high resistance at $63^{\circ} \mathrm{C}$ and moderate resistance at $72^{\circ} \mathrm{C}$. However, using $80^{\circ} \mathrm{C}$ for $30 \mathrm{~min}$ or $90^{\circ} \mathrm{C}$ for 2 min resulted in complete inactivate of phages (Pujato et al., 2014). In comparison, in the present study, phage P1 exhibited a relatively low resistance to heat treatment because it was completely inactivated in 5 and $10 \mathrm{~min}$ at 90 and $72^{\circ} \mathrm{C}$, respectively. As previously reported, most phages cannot survive heating at $90^{\circ} \mathrm{C}$. Mercanti et al. (2012) reported that 2 temperate phages, SiLp84 and $\Phi$ iLp1308, isolated from mitomycin-C induction of Lactobacillus paracasei strains 84 and CNRZ1308, were susceptible to $90^{\circ} \mathrm{C}$ when heated for $2 \mathrm{~min}$. Increasing the temperature from 63 to $90^{\circ} \mathrm{C}$ therefore improved phage inactivation. Heat treatment at $90^{\circ} \mathrm{C}$ for $5 \mathrm{~min}$ was sufficient for inactivation of lactobacilli phages 


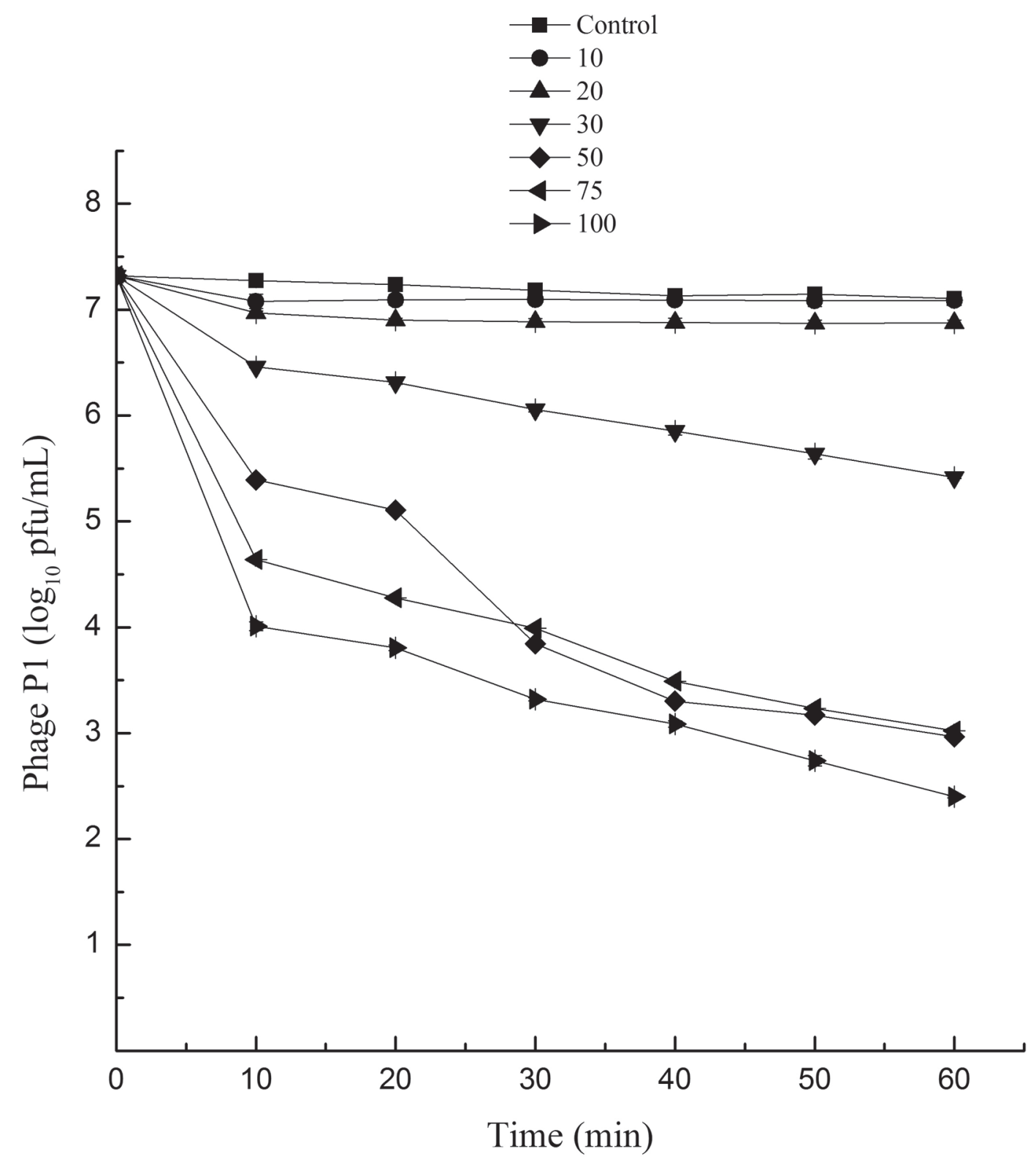

Figure 2. Inactivation kinetics of phage P1 $\left(\log _{10}\right.$ plaque-forming units/mL) with ethanol $[0$ (control) to $100 \%]$. Values are the mean of 3 determinations; some error bars are too small to be visible and are \pm 0.07 .

(Briggiler Marcó et al., 2009; Guglielmotti et al., 2012) but not effective for some Lactococcus phages. Atamer et al. (2009) reported that Lactococcus lactis phages P1532 and P680 could not be completely inactivated when heated for $5 \mathrm{~min}$ at 97 and $95^{\circ} \mathrm{C}$, respectively.

For Lactobacillus phage $\mathrm{P} 1$, we observed that the nature of the suspension medium provided varying protective effects. In the present study, RSM provided the maximum protective effect. It has been suggested that some milk properties, including buffering capacity and protein or salt content, may play a protective role during heating and therefore be responsible for the higher thermal resistance observed for some phages (Quiberoni et al., 2003). Briggiler Marcó et al. (2009) also reported high thermal resistance for L. plantarum phages (ATCC8014-B2, FAGK1, FAGK2) in RSM and EM-glucose media, whereas Ebrecht et al. (2010) reported that RSM could provide protective effects to $L$. delbrueckii bacteriophages (Cb1/204, Cb1/342, BYM, YAB, Ib3). In contrast, Capra et al. (2004) evaluated the thermal resistance of 2 Lactobacillus casei and Lactobacillus paracasei bacteriophages PL-1 and J-1, using MRS broth, RSM, and TMG buffer but reported that no clear difference in resistance was demonstrated by 


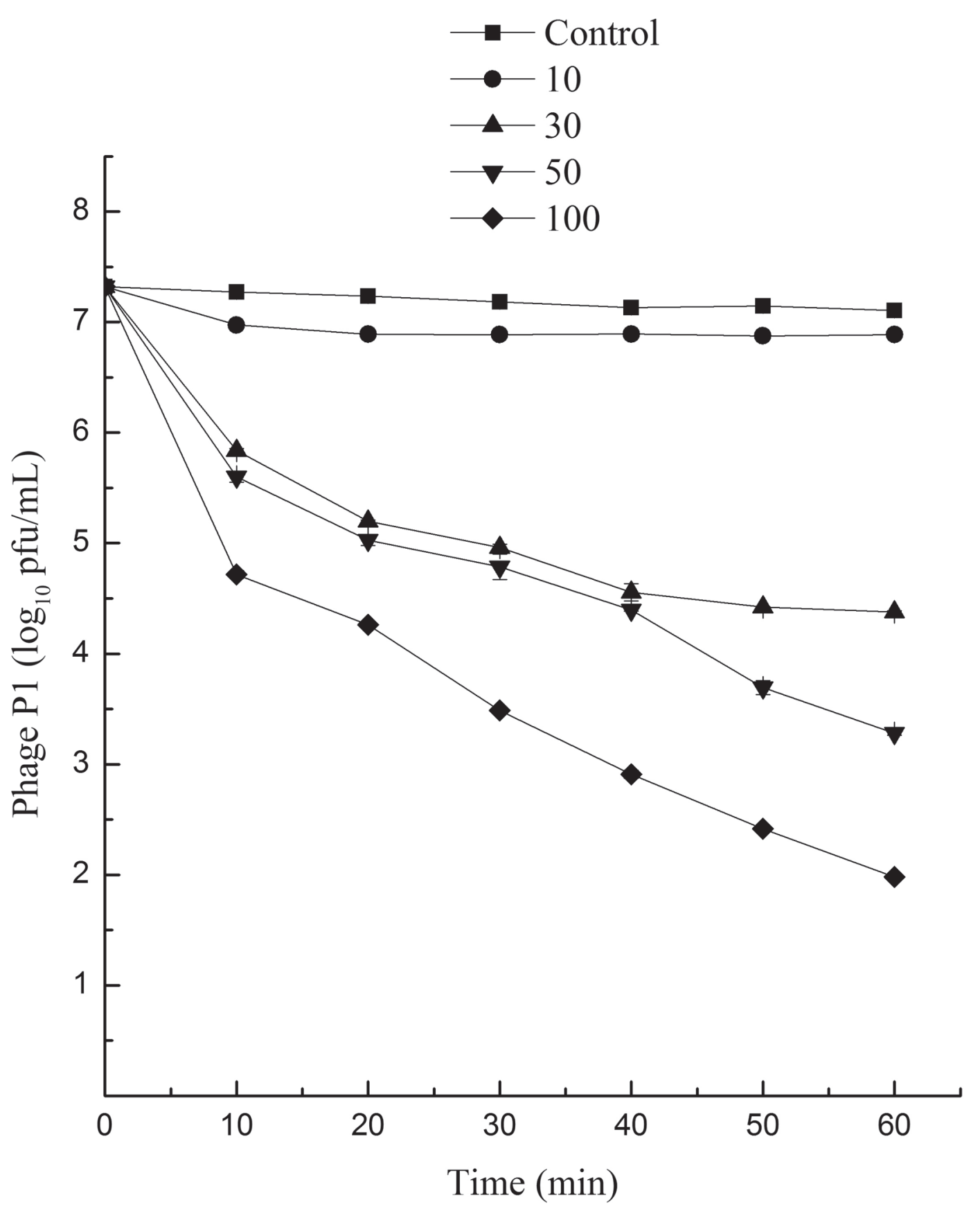

Figure 3. Inactivation kinetics of phage P1 $\left(\log _{10}\right.$ plaque-forming units $/ \mathrm{mL}$ ) with isopropanol [0 (control) to 100\%]. Values are the mean of 3 determinations. Some error bars are too small to be visible and are \pm 0.12 .

any of the suspension media. Binetti and Reinheimer (2000) evaluated the thermal resistance of 5 autochthonal bacteriophages of Streptococcus thermophilus isolated from Cuartirolo cheese whey and yogurt, using enriched tryptic soy broth, reconstituted commercial nonfat skim milk, and Tris magnesium gelatin buffer. Those authors reported that none of the media resulted in significant differences in phage resistance. It is pos- sible, therefore, that protective effects exhibited by different media are phage-specific.

In this study, the effects of several common biocides used in the dairy industry and in laboratory research were evaluated using phage P1. In our previous study (results not published), we reported that phage activity at 25 and $40^{\circ} \mathrm{C}$ did not appear to differ; therefore, a treatment temperature of $25^{\circ} \mathrm{C}$ was arbitrarily chosen. 


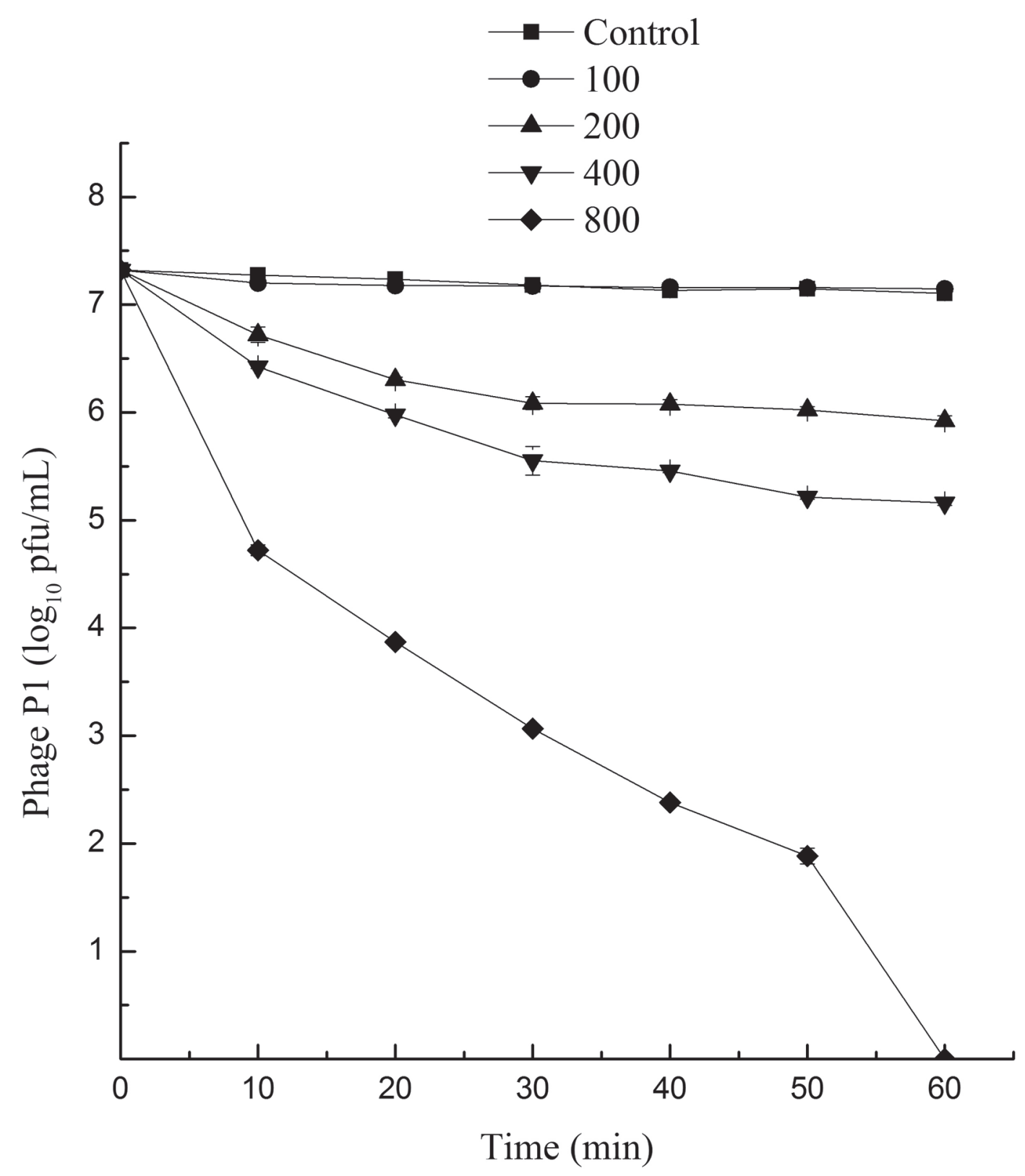

Figure 4. Inactivation kinetics of phage P1 $\left(\log _{10}\right.$ plaque-forming units/mL) with sodium hypochlorite $[0$ (control) to $800 \mathrm{mg} / \mathrm{L}]$. Values are the mean of 3 determinations. Some error bars are too small to be visible and are \pm 0.14 .

In addition, it is well recognized that higher temperature use with some biocides (e.g., peracetic acid and chlorine) increases their volatility, contributing to eye and skin irritation of plant personnel. Among the biocides tested, sodium hypochlorite was the most effective; $800 \mathrm{mg} / \mathrm{L}$ completely inactivated phage P1 in $60 \mathrm{~min}$, with $T_{99}=7.70 \mathrm{~min}$. However, this chlorine concentration is 2 to 3 times higher than that allowed in the food industry (Briggiler Marcó et al., 2009) and therefore could not be used for commercial purposes. However, it could be of use in future pilot- or laboratory-scale studies. Briggiler Marcó et al. (2009) also reported that a $30-\mathrm{min}$ exposure to $800 \mathrm{mg} / \mathrm{L}$ of residual free chlorine was necessary to totally inactive L. plantarum phages B1, FAGK1, FAGK2, whereas 15 min was necessary for phage B2 (Briggiler Marcó et al., 2009). For total activation of $L$. casei and L. paracasei phages, $5 \mathrm{~min}$ at $800 \mathrm{mg} / \mathrm{L}$ was necessary (Capra et al., 2004). In contrast, some L. delbrueckii, Lactobacillus helveticus, Lactococcus lactis, and S. thermophilus phages could be completely eliminated using $100 \mathrm{mg} / \mathrm{L}$ of free residual chlorine (Quiberoni et al., 1999; Binetti 


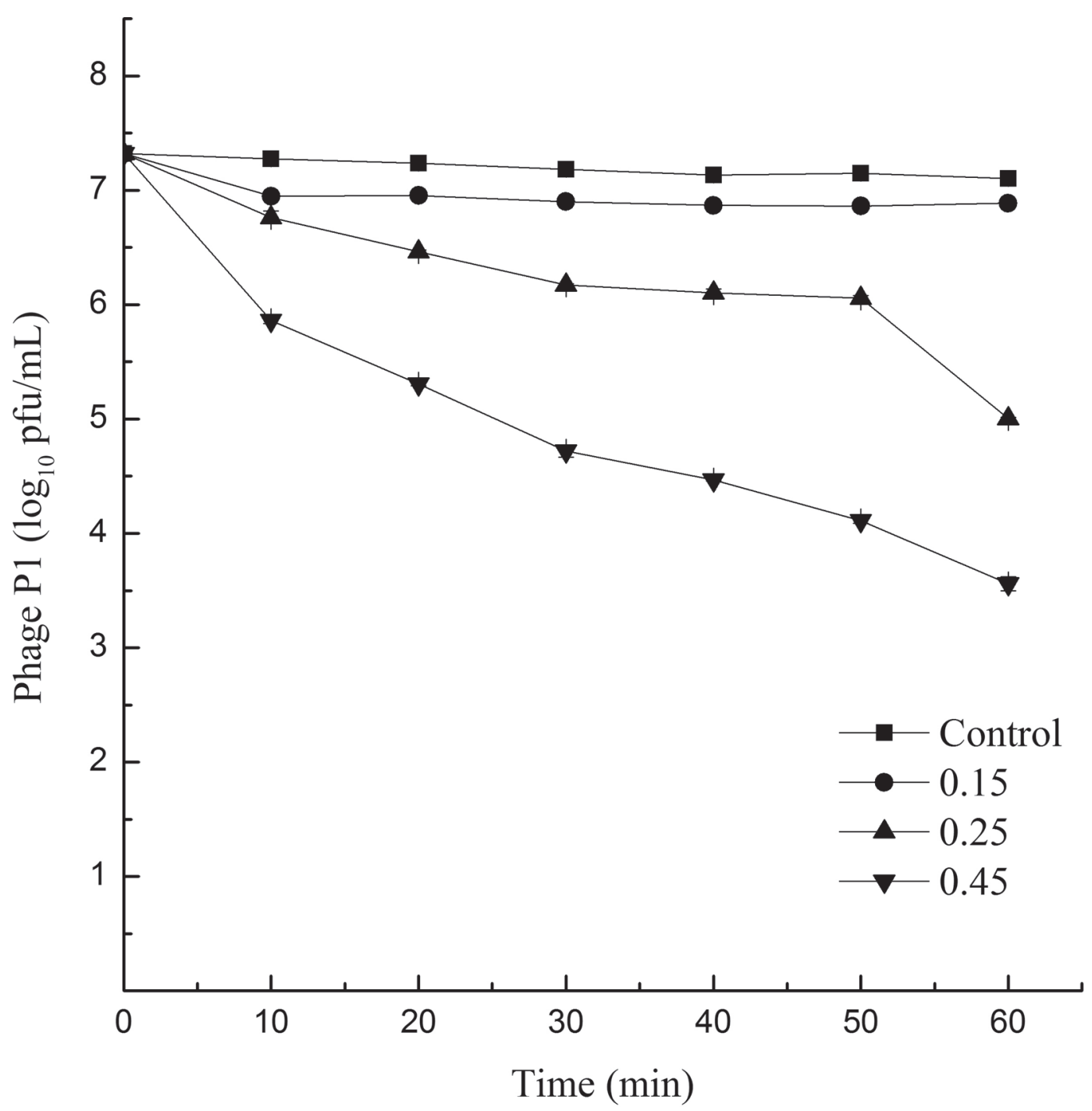

Figure 5. Inactivation kinetics of phage P1 $\left(\log _{10}\right.$ plaque-forming units/mL) with peracetic acid [0 (control) to $\left.0.45 \%\right]$. Values are the mean of 3 determinations. Some error bars are too small to be visible and are \pm 0.07 .

and Reinheimer, 2000; Suárez and Reinheimer, 2002; Ebrecht et al., 2010). Of note, L. bulgaricus phage Ib3 represents one of the most resistant phage to sodium hypochlorite, requiring at least $45 \mathrm{~min}$ of exposure and a minimum concentration of $1,200 \mathrm{mg} / \mathrm{L}$ of residual free chlorine for complete inactivation (Quiberoni et al., 2003). Maillard et al. (1998) suggested that sodium hypochlorite may cause phage inactivation via aggregation of tail proteins or that it could result in structural alterations to the capsid, possibly releasing nucleic acid into the surrounding medium.

Compared with other LAB phages, phage P1 appeared less sensitive to both ethanol and isopropanol. During a 60-min treatment, ethanol (100\%) resulted in a $\sim 4$.7-log reduction, whereas $100 \%$ isopropanol re- sulted in a $\sim 5.2-\log$ reduction. Complete inactivation was therefore not achieved. Treatment of phage using 10,20 , or $30 \%$ ethanol, and $10 \%$ isopropanol resulted in minimal inactivation. Similar results have been reported for L. casei and L. paracasei phages (Capra et al., 2004), L. plantarum phages (Briggiler Marcó et al., 2009), and L. delbrueckii (Ebrecht et al., 2010). However, for some LAB phages, ethanol or isopropanol was more effective. For example, the $T_{99}$ value for $S$. thermophilus phages CYM, 0BJ, and 031-D in 75\% ethanol was less than $5 \mathrm{~min}$, and the phages were undetectable after a 15-min incubation with 75 or $100 \%$ ethanol (Binetti and Reinheimer, 2000). Lactobacillus delbrueckii phage LL-H could also be completely inactivated after a 30-min treatment with $75 \%$ ethanol (Quiberoni et 
al., 2003). It has been suggested that the antibacterial property of alcohol is because it alters the lipid fraction of the plasma membrane and that naked phages are likely to be naturally more resistant than bacteria to an ethanol challenge (Maillard et al., 1996; Guglielmotti et al., 2012). Ethanol has been used in the sanitation of airflow units or on laboratory surfaces; however, to increase effectiveness, it is suggested that it be used together with other biocides (Briggiler Marcó et al., 2009).

Peracetic acid is viricidal and has been widely documented as an economical and practical agent for LAB phage inactivation, including those targeting $L$. plantarum (Briggiler Marcó et al., 2009), L. delbrueckii (Ebrecht et al., 2010), L. casei, L. paracasei (Mercanti et al., 2012), S. thermophilus (Binetti and Reinheimer, 2000), and L. lactis (Suárez and Reinheimer, 2002). Major advantages include its ability to quickly and efficiently inactivate most vegetative microorganisms, its resistance to catalase and peroxidase, and degradation into environmentally friendly products. Peracetic acid maintains its activity over wide temperature $\left(0-40^{\circ} \mathrm{C}\right)$ and $\mathrm{pH}(3.0-7.5)$ ranges and in hard water, and it is not affected by protein residues. These properties allow for its safe use in the food industry including cleaning-inplace (CIP) practices (Guglielmotti et al., 2012). The low $\mathrm{pH}(\sim 1.5-2)$ has been shown to inactivate phage (Mercanti et al., 2012). Peracetic acid is a powerful oxidizing agent that causes irreparable damage to various microbial macromolecules including proteins. It has the ability to penetrate cellular membranes, causing internal $\mathrm{pH}$ changes that eventually lead to death. In phage, complete rupture of nucleic acid is accomplished, resulting in inactivation. Whether this occurs inside the capsid or after the DNA is released due to capsid structural damage remains unclear (Guglielmotti et al., 2012). In the present investigation, peracetic acid at $0.15 \%$ for 60 min exhibited little inactivation toward phage $\mathrm{P} 1$, and increasing the concentration to $0.45 \%$ for 60 min resulted in only a $\sim 4.0-\log$ reduction. Thus, it appears that phage P1 was somewhat resistant to peracetic acid, which further highlights the importance of recognizing phage-specific biocides. Higher concentrations of peracetic acid could be used, but similar to chlorine, it is a strong irritant, affecting eyes, skin, and the respiratory system. Workers would therefore be adversely affected.

\section{CONCLUSIONS}

We evaluated the resistance of Lactobacillus virulent phage $\mathrm{P} 1$, isolated from a slow fermentation containing of L. plantarum IMAU10120, with respect to various thermal and biocide treatments routinely used in dairy plants and laboratories. Phage P1 showed a relatively low resistance to heat and could be completely inactivated in 5 and $10 \mathrm{~min}$ at 90 and $72^{\circ} \mathrm{C}$, respectively. Among the media examined, reconstituted skim milk provided the best heat protection. Resistance to biocides appeared high; sodium hypochlorite at $800 \mathrm{mg} / \mathrm{L}$ was required for total inactivation within 60 min. During the same period, treatment with $100 \%$ ethanol and isopropanol did not result in complete lethality. Phage P1 also expressed high resistance toward peracetic acid, surviving treatment at $0.45 \%$. The results of this study should prove helpful in future studies on phage resistance, especially in the design of intervention strategies for the reduction of phage infections in laboratories and dairy plants.

\section{ACKNOWLEDGMENTS}

This work was supported by Natural Science Foundation of China (Beijing; grant no. 31301517, 31660457) and Natural Science Foundation of Inner Mongolia, China (Hohhot; grant no. 2017MS0308).

\section{REFERENCES}

Atamer, Z., J. Dietrich, M. Müller-Merbach, H. Neve, K. J. Heller, and J. Hinrichs. 2009. Screening for and characterization of Lactococcus lactis bacteriophages with high thermal resistance. Int. Dairy J. 19:228-235.

Binetti, A. G., and J. A. Reinheimer. 2000. Thermal and chemical inactivation of indigenous Streptococcus thermophilus bacteriophages isolated from Argentinian dairy plants. J. Food Prot. 63:509-515.

Briggiler Marcó, M., G. L. de Antoni, J. A. Reinheimer, and A. Quiberoni. 2009. Thermal, chemical, and photocatalytic inactivation of Lactobacillus plantarum bacteriophages. J. Food Prot. 72:10121019.

Briggiler Marcó, M., J. E. Garneau, D. Tremblay, A. Quiberoni, and S. Moineau. 2012. Characterization of two virulent phages of Lactobacillus plantarum. Appl. Environ. Microbiol. 78:8719-8734.

Capra, M. L., A. Quiberoni, and J. A. Reinheimer. 2004. Thermal and chemical resistance of Lactobacillus case $i$ and Lactobacillus paracasei bacteriophages. Lett. Appl. Microbiol. 38:499-504.

Chen, X., Y. Xi, H. Zhang, Z. Wang, M. Fan, Y. Liu, and W. Wu. 2016. Characterization and adsorption of Lactobacillus virulent phage P1. J. Dairy Sci. 99:6995-7001.

de Vries, M. C., E. E. Vaughan, M. Kleerebezem, and W. M. de Vos. 2006. Lactobacillus plantarum -Survival, functional and potential properties in the human intestinal tract. Int. Dairy J. 16:1018 1028.

Ebrecht, A. C., D. M. Guglielmotti, G. Tremmel, J. A. Reinheimer, and V. B. Suárez. 2010. Temperate and virulent Lactobacillus delbrueckii bacteriophages: Comparison of their thermal and chemical resistance. Food Microbiol. 27:515-520.

Guglielmotti, D. M., D. J. Mercanti, J. A. Reinheimer, and A. D. L. Quiberoni. 2012. Review: Efficiency of physical and chemical treatments on the inactivation of dairy bacteriophages. Front. Microbiol. 2:282.

Karasu, N., O. Şimşek, and A. H. Çon. 2010. Technological and probiotic characteristics of Lactobacillus plantarum strains isolated from traditionally produced fermented vegetables. Ann. Microbiol. 60:227-234.

Lynch, C. M., D. D. Muir, J. M. Banks, P. L. H. Mcsweeney, and P. F. Fox. 1999. Influence of adjunct cultures of Lactobacillus paracasei 
ssp. paracasei or Lactobacillus plantarum on cheddar cheese ripening. J. Dairy Sci. 82:1618-1628.

Madera, C., C. Monjardín, and J. E. Suárez. 2004. Milk contamination and resistance to processing conditions determine the fate of $\mathrm{Lac}$ tococcus lactis bacteriophages in dairies. Appl. Environ. Microbiol. 70:7365-7371.

Maillard, J. Y., T. S. Beggs, M. J. Day, R. A. Hudson, and A. D. Russell. 1996. Damage to Pseudomonas aeruginosa PAO1 bacteriophage F116 DNA by biocides. J. Appl. Bacteriol. 80:540-544.

Maillard, J. Y., A. C. Hann, V. Baubet, and R. Perrin. 1998. Efficacy and mechanisms of action of sodium hypochlorite on Pseudomonas aeruginosa PAO1 phage F116. J. Appl. Microbiol. 85:925-932.

Mercanti, D. J., D. M. Guglielmotti, F. Patrignani, J. A. Reinheimer, and A. Quiberoni. 2012. Resistance of two temperate Lactobacillus paracase $i$ bacteriophages to high pressure homogenization, thermal treatments and chemical biocides of industrial application. Food Microbiol. 29:99-104.

Moineau, S. 1999. Applications of phage resistance in lactic acid bacteria. Antonie van Leeuwenhoek 76:377-382.

Neviani, E., D. Carminati, and G. Giraffa. 1992. Selection of some bacteriophage and lysozeme-resistant variants of Lactobacillus helveticus CNRZ892. J. Dairy Sci. 75:905-913.
Pujato, S. A., D. M. Guglielmotti, H. W. Ackermann, F. Patrignani, R. Lanciotti, J. A. Reinheimer, and A. Quiberoni. 2014. Leuconostoc bacteriophages from blue cheese manufacture: long-term survival, resistance to thermal treatments, high pressure homogenization and chemical biocides of industrial application. Int. J. Food Microbiol. 177:81-88.

Quiberoni, A., D. M. Guglielmotti, and J. A. Reinheimer. 2003. Inactivation of Lactobacillus delbrueckii bacteriophages by heat and biocides. Int. J. Food Microbiol. 84:51-62.

Quiberoni, A., V. B. Suárez, A. G. Binetti, and J. A. Reinheimer. 2011. Bacteriophages. Pages 430-438 in Encyclopedia of Dairy Science. Vol. 1. 2nd ed. J. Fuquay, P. Fox, and P. McSweeney, ed. Academic Press, Elsevier Science, Cambridge, MA.

Quiberoni, A., V. B. Suárez, and J. A. Reinheimer. 1999. Inactivation of Lactobacillus helveticus bacteriophages by thermal and chemical treatments. J. Food Prot. 62:894-898.

Suárez, V. B., and J. A. Reinheimer. 2002. Effectiveness of thermal treatments and biocides in the inactivation of Argentinian Lactococcus lactis phages. J. Food Prot. 65:1756-1759.

Zhang, X., Y. Lan, W. Jiao, Y. Li, L. Tang, Y. Jiang, W. Cui, and X. Qiao. 2015. Isolation and characterization of a novel virulent phage of Lactobacillus casei ATCC 393. Food Environ. Virol. 7:333-341. 